\title{
International survey to assess women's attitudes regarding choice of daily versus nondaily female hormonal contraception
}

This article was published in the following Dove Press journal:

International Journal of Women's Health

3 April 2014

Number of times this article has been viewed

\section{Diana Mansour}

New Croft Centre, Newcastle Hospitals Community Health, Newcastle upon Tyne, UK
Correspondence: Diana Mansour New Croft Centre, Market Road (East), Newcastle upon Tyne, NEI 6ND, UK

Tel +44 I 912292862

Fax +44 I9I2 292979

Email diana.mansour@nuth.nhs.uk
Background: The availability of reliable contraception tailored to suit women's needs and lifestyles is an essential step in addressing unintended pregnancy and its substantial human and financial costs. The daily combined oral contraceptive pill has been the short-acting hormonal contraceptive of choice for the last 50 years. However, for some women, this may be neither suitable nor optimal.

Methods: Here we report the findings of a large, online, questionnaire-based study conducted in Brazil, France, Germany, Italy, and the USA. The study was designed to assess women's attitudes, beliefs, and unmet needs regarding current hormonal contraceptive options via an anonymous online survey. Women eligible for contraception were required to respond to questions using either a binary (yes/no) or seven-point scale (1, complete disagreement; 7, complete agreement). Women were also asked about other relevant issues, such as lifestyle, perception of menstruation and pregnancy, level of education, and relationship with their health care professional.

Results: In total, 12,094 women were questioned, of whom $68 \%$ required contraception. Overall, $28 \%$ of women expressed an interest in novel contraceptive products, and $49 \%$ stated that they would prefer a nondaily method. Although many women expressed satisfaction with the pill, daily intake was thought to be burdensome, resulting in irregular and ineffective usage. However, many women continued to choose the pill due to lack of consideration of and education about other options. Approximately half of the women wished to conceive in the near future.

Conclusion: The findings indicate that nearly half of respondents would prefer a nondaily form of contraception. Furthermore, approximately half of respondents wished to conceive in the near future, suggesting that they are unlikely to favor long-acting options. Effective education on contraceptive choices may help women to find the method that best suits their needs, thus improving contraceptive compliance.

Keywords: female contraception, contraceptive options, hormonal contraceptives, survey, women's attitudes

\section{Introduction}

Unintended pregnancy is a worldwide problem and may result from contraceptive misuse and failure. ${ }^{1}$ The availability of reliable contraception that is tailored to suit individual women's needs and lifestyles is an essential step in addressing unintended pregnancy and its substantial human and financial costs. The daily combined oral contraceptive pill has been the short-acting hormonal contraceptive of choice for the last 50 years. However, for some women this may not be a suitable or optimal contraceptive choice. 
Studies investigating women's views on contraception have reported risk-taking behavior in terms of compliance. ${ }^{2-4}$ Although efficacious when used correctly, adherence to oral contraceptive (OC) regimens has been shown to be poor, with many women repeatedly missing tablets. ${ }^{2}$ In an effort to improve compliance, long-acting contraceptive alternatives (such as the injection) and short-acting nondaily alternatives (such as the patch or vaginal ring) that minimize the frequency of dosing are becoming increasingly popular.

The success of new, nondaily, hormonal contraceptive products, such as the levonorgestrel-releasing intrauterine system/intrauterine device and the etonogestrel implant, has highlighted the need for additional nondaily and nonoral hormonal contraceptive choices. Nonetheless, study data have shown that although many women discuss combined OCs with their health care providers, few women discuss the nonpill alternatives. ${ }^{5}$ Evidence also shows that some women are poorly informed about such methods, and tend to have firm but incorrect beliefs about their safety and side effects. ${ }^{4,5}$ These erroneous and often negative views have been shown to influence women's decisions strongly regarding contraceptives. ${ }^{6}$

The aim of the present study was to gain an indepth understanding of women's attitudes, beliefs, and, most importantly, unmet needs in relation to current hormonal contraceptive options in five European and American countries.

\section{Materials and methods}

The study was designed to assess women's attitudes, beliefs, and unmet needs around current hormonal contraceptive options via an anonymous online survey. Women eligible for contraception were required to respond to questions using either a binary (yes/no) or seven-point scale (1, complete disagreement; 7, complete agreement). Women were also asked about other relevant issues, such as lifestyle, perception of menstruation and pregnancy, level of education, and relationship with their health care professional.

The survey was conducted in 2011 in a target group of women from Brazil, France, Germany, Italy, and the USA. These countries were selected because they represent large hormonal contraceptive markets in the developed world. The online interviews took approximately 45 minutes using only precoded questions focusing on the convenience, efficacy, tolerability, cost, social perception, and hormonal content of currently available female contraceptive choices. The study did not seek to explore fully any safety concerns that women may or may not have had with their current contraceptive methods.
In order to check consistency of response, validation questions were included in the survey.

Women were recruited online, and respondents were primarily sourced from existing panels of women who indicated a willingness to answer online questionnaires. A maximum of one woman per household was permitted to respond, and all questionnaire responses were anonymous.

\section{Participants}

A total of 12,094 women aged 15-49 years were sampled for this study, with all study analyses conducted on weighted sample data. Weighting was based on population data obtained from the World Bank, and from the 2006-2008 National Survey on Family Growth (USA), the 2006 Bayer Market Segmentation Study (France), the 2007 German Federal Ministry for Health Survey (Germany), and data from the Brazilian Ministry of Health (Brazil). In addition, samples from each country were designed to contain a minimum of $40 \%$ of women aged 15-34 years with the aim of gaining robust data from those with the greatest need for contraception. The lower limit was selected because women $<15$ years of age are less likely to be engaged in sexual activity compared with those $\geq 15$ years of age; the upper limit reflects the decline in fertility that occurs as women age. ${ }^{7}$ In addition, because socially deprived women in Brazil (social class D and below) have limited access to both health care and the Internet, recruitment and analysis were confined to social classes $\mathrm{A}-\mathrm{C}$, where gross household income is more than 2,000 reals per month. Women from all other countries were selected to give a representative sample according to age, education, income, and regional distribution. Members of existing panels were contacted via email with a request to complete a 13-question screener to determine eligibility for the main survey. This screener gathered data from women in the initial sample in order to remove from the study those who were infertile or did not require contraception (including those who had undergone surgical sterilization or hysterectomy). Women were also removed if they were postmenopausal, opposed to contraception, or in a monogamous relationship with a partner who had been sterilized.

In line with standard market research practice, eligible respondents were offered a small financial incentive (typically US\$20-\$50) to complete the survey. The study methodology was subject to the sponsor's stringent internal legal and medical review process, which is based on best practice guidelines from the Prescription Medicines Code of Practice Authority. ${ }^{8}$ Financial support was provided by Bayer HealthCare AG, Wuppertal, Germany. 


\section{Statistical analysis}

Specific questions regarding women's openness to hormonal contraception, and uterine bleeding or pain, were presented to all women included in the survey. Only women seeking contraception and who were not sterilized, hysterectomized, or with a partner who had undergone a vasectomy were included in the statistical analyses. Answers to the questions that used a binary (yes/no) scale were analyzed using the independent two-tailed $t$-test, and for the questions with a seven-point scale (1, complete disagreement; 7, complete agreement), the chi-squared test was used.

\section{Results}

\section{Patient demographics}

\section{and relationship information}

In total, 12,094 women were included in the survey. Women's ages ranged from 15 to 49 years, with nearly $50 \%$ of these aged 30 years or younger (Table 1). While $50 \%$ of respondents lived in urban areas, there was significant variation between countries, with greater urban living in Brazil than in the USA. The majority of respondents $(83 \%)$ had a household income $\geq 20,000$ Euros.

Overall, $42 \%$ of women surveyed were married. A total of $54 \%$ of those surveyed had no children and, of those who had started families, only $7 \%$ had more than two children.

Globally, $83 \%$ of women reported that they were sexually active and engaged in sexual activity at least once a week. Women also reported an average of two partners per year. A large majority $(76 \%)$ of respondents indicated that they were currently in a committed relationship and had regular sexual activity.

\section{Current contraceptive use and planned pregnancy}

Figure 1 shows the cumulative contraceptive use reported by the study population. A total of $56 \%$ of respondents chose hormonal contraception, $17 \%$ chose barrier contraception, $6 \%$ chose other forms of contraception, and $20 \%$ reportedly used no contraception. Although nonuse of contraception appeared high, this was consistent across countries, with Italy and the USA having the highest degree of nonusage at $24 \%$ and $21 \%$, respectively.

Most women surveyed indicated that they did not wish to become pregnant immediately, but half regarded children as critical to their future. While almost $25 \%$ of women indicated that they had no plans to become pregnant, $41 \%$ reported that they were planning a pregnancy within $1-3$ years.
Table I Breakdown of total study participant population ${ }^{a}$ by demographic characteristics and method of contraception used $(n=12,094)$

\begin{tabular}{|c|c|}
\hline Characteristic & n (\%) \\
\hline \multicolumn{2}{|l|}{ Age (years) } \\
\hline $45+$ & $1,572(13)$ \\
\hline $30-44$ & $5,118(42)$ \\
\hline $15-29 \mathrm{~b}$ & $5,405(45)$ \\
\hline \multicolumn{2}{|c|}{ Country of residence } \\
\hline USA & $5,318(44)$ \\
\hline Brazil & $2,436(20)$ \\
\hline Germany & $1,674(14)$ \\
\hline Italy & $\mathrm{I}, 357(\mathrm{II})$ \\
\hline France & $\mathrm{I}, 308(\mathrm{II})$ \\
\hline \multicolumn{2}{|l|}{ Residence location } \\
\hline Rural area & $5,849(19)$ \\
\hline Suburban area & $3,993(33)$ \\
\hline Urban area & $2,253(48)$ \\
\hline \multicolumn{2}{|c|}{ Number of children } \\
\hline None & $6,583(54)$ \\
\hline $\mathrm{I}-2$ & $4,64 \mid(38)$ \\
\hline $3+$ & $871(7)$ \\
\hline \multicolumn{2}{|c|}{ Household income (Euros) } \\
\hline$>75,000$ & I,502 (I2) \\
\hline $37,500-75,000$ & $4,036(33)$ \\
\hline $20,000-37,500$ & 4,591 (38) \\
\hline$\leq 20,000$ & $1,965(16)$ \\
\hline \multicolumn{2}{|l|}{ Relationship status } \\
\hline Committed & $9,243(76)$ \\
\hline Single & $2,005(17)$ \\
\hline Dating & $846(7)$ \\
\hline \multicolumn{2}{|l|}{ Sexually active } \\
\hline Yes & $9,982(83)$ \\
\hline No & $2,112(17)$ \\
\hline \multicolumn{2}{|c|}{ Method of contraception ${ }^{c}$} \\
\hline Hormonal & $6,832(56)$ \\
\hline Barrier & $2,018(17)$ \\
\hline None & $2,447(20)$ \\
\hline Others & $767(6)$ \\
\hline
\end{tabular}

Notes: aecause some study participants did not provide responses to all of the survey questions, the total respondent numbers for each group (eg, age, country, residence location) may vary; ${ }^{\text {in }}$ the USA, France, and Brazil, only women aged $18-49$ years were recruited; 'total percentage is not $100 \%$ due to rounding.

\section{Awareness of contraceptive methods}

Given that one of the main aims of this study was to assess women's unmet contraceptive needs, it was important to assess their awareness of currently available contraceptive choices. The majority of women $(72 \%)$ indicated that they were aware of at least four contraceptive methods, although $9 \%$ were aware of only one or two methods. OCs and the male condom were the two predominant methods used globally ( $44 \%$ and $37 \%$ usage, respectively), with other methods having a lower uptake.

\section{Drivers of contraceptive choice}

Three primary drivers of women's choice of contraceptive were identified. Overall, a 99\% level of contraceptive efficacy 


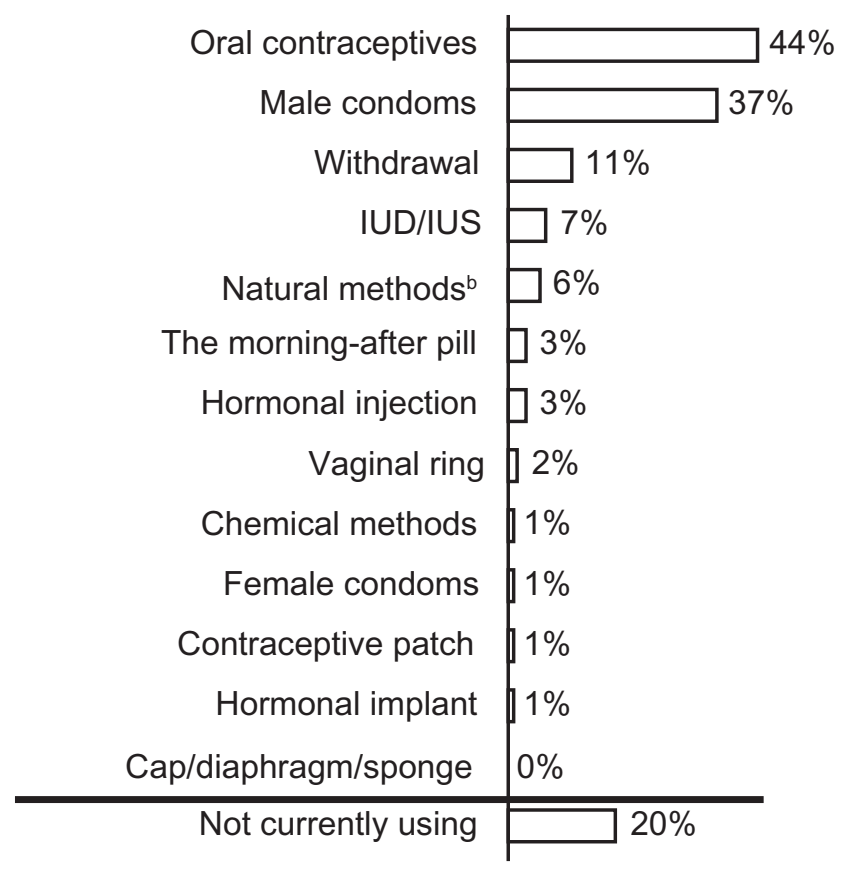

Figure I Current contraception usage ${ }^{\text {a }}$ (excludes women who were postmenopausal, infertile, or who had been sterilized by tubal ligation, had a sterilization implant at the time of questionnaire completion, those in a monogamous relationship whose partner had been sterilized by vasectomy, and those opposed to use of contraception). Because respondents were able to choose multiple options, percentages may not add up to $100 \%$ in each category. Responses to the questions were binary (yes/no).

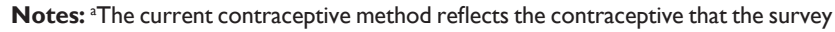
population were using at the time when the study was conducted; bnatural methods include the basal temperature method and the rhythm and calendar methods. Abbreviation: IUD/IUS, intrauterine device/system.

was the predominant factor, with $76 \%$ of women indicating that this was very important. Furthermore, $37 \%$ of respondents indicated that the level of efficacy was the single most important factor in contraceptive choice. A minimal impact on health and well-being was also identified as a key driver in women's choice of contraceptive, including a desire to use methods that have no impact on long-term health (72\%), minimal side effects (72\%), no weight gain $(65 \%)$, and no decrease in sex drive (63\%). The third primary driver for contraceptive choice was expense (48\%). However, this driver differed between countries, with $52 \%$ and $18 \%$ of Brazilian and French women, respectively, quoting it as an important factor.

Women indicated a strong desire for a flexible method of contraception, with $73 \%$ of respondents saying that they wanted to stop using their contraceptive at the moment they choose (Figure 2). Additionally, 28\% of women expressed an interest in trying the latest products (not illustrated in the figures or tables), and $49 \%$ stated that they would prefer a nondaily method. Moreover, $18 \%$ of women overall indicated that they would prefer a contraceptive that was taken just before they had sex. However, as a result of this desire for flexibility, only $18 \%$ of women indicated that longer-term solutions (methods active for at least one year) were ideal for meeting their needs (Figure 3).

A large proportion of women expressed a desire to continue having regular periods during contraceptive use. Overall, almost $49 \%$ of respondents believed the absence of monthly menstruation to be unnatural, with the frequency higher in France (62\%) and Italy (68\%) compared with other countries ( $42 \%-49 \%)$. Similarly, $48 \%$ of respondents considered the absence of monthly menstruation to be unhealthy, with the highest frequency in Italy (74\%) and the lowest in Germany (41\%) and the USA (40\%). For $67 \%$ of respondents, menstruation was regarded as a sign that they were healthy (ranging from 53\% in Brazil to $74 \%$ in the USA).

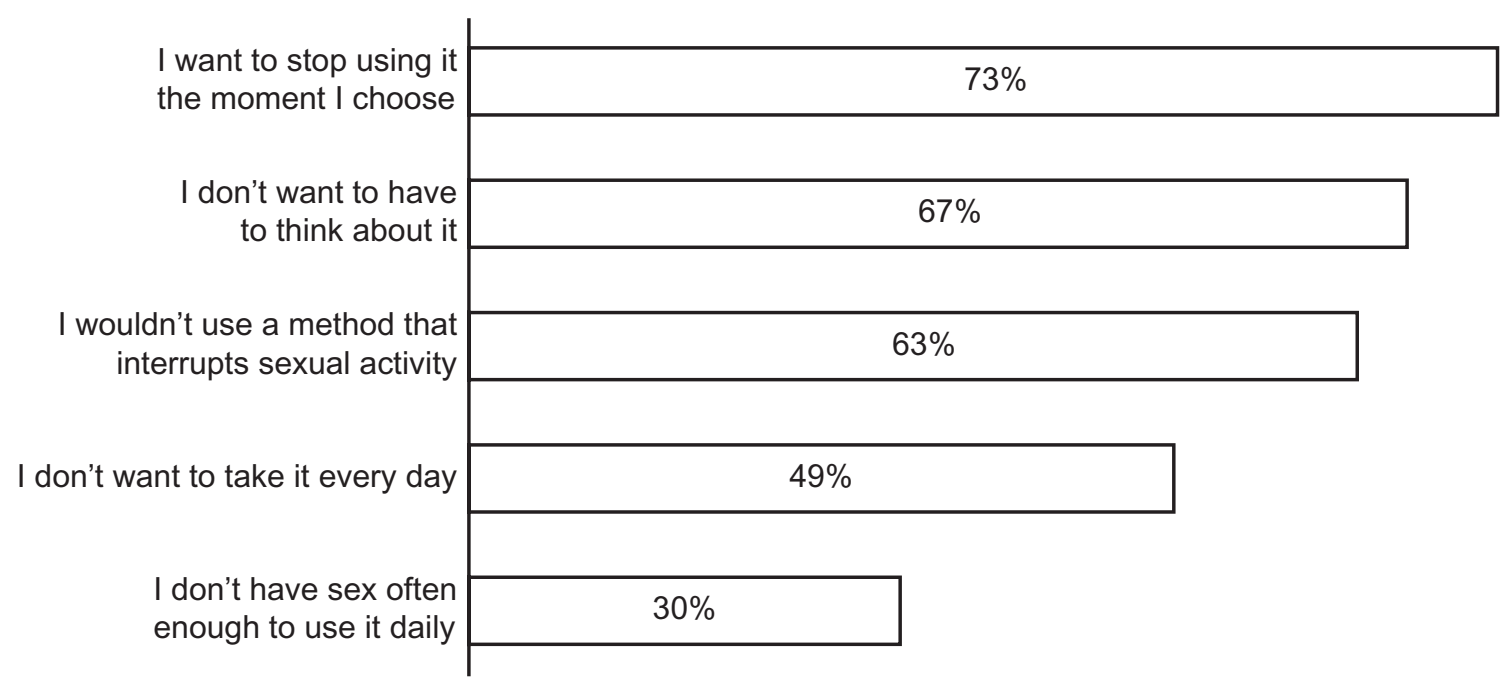

Figure 2 Responses to the survey question on what is wanted from a contraceptive method from the perspective of the user's needs. Responses to the questions were given on a seven-point scale (I, complete disagreement; 7, complete agreement). 


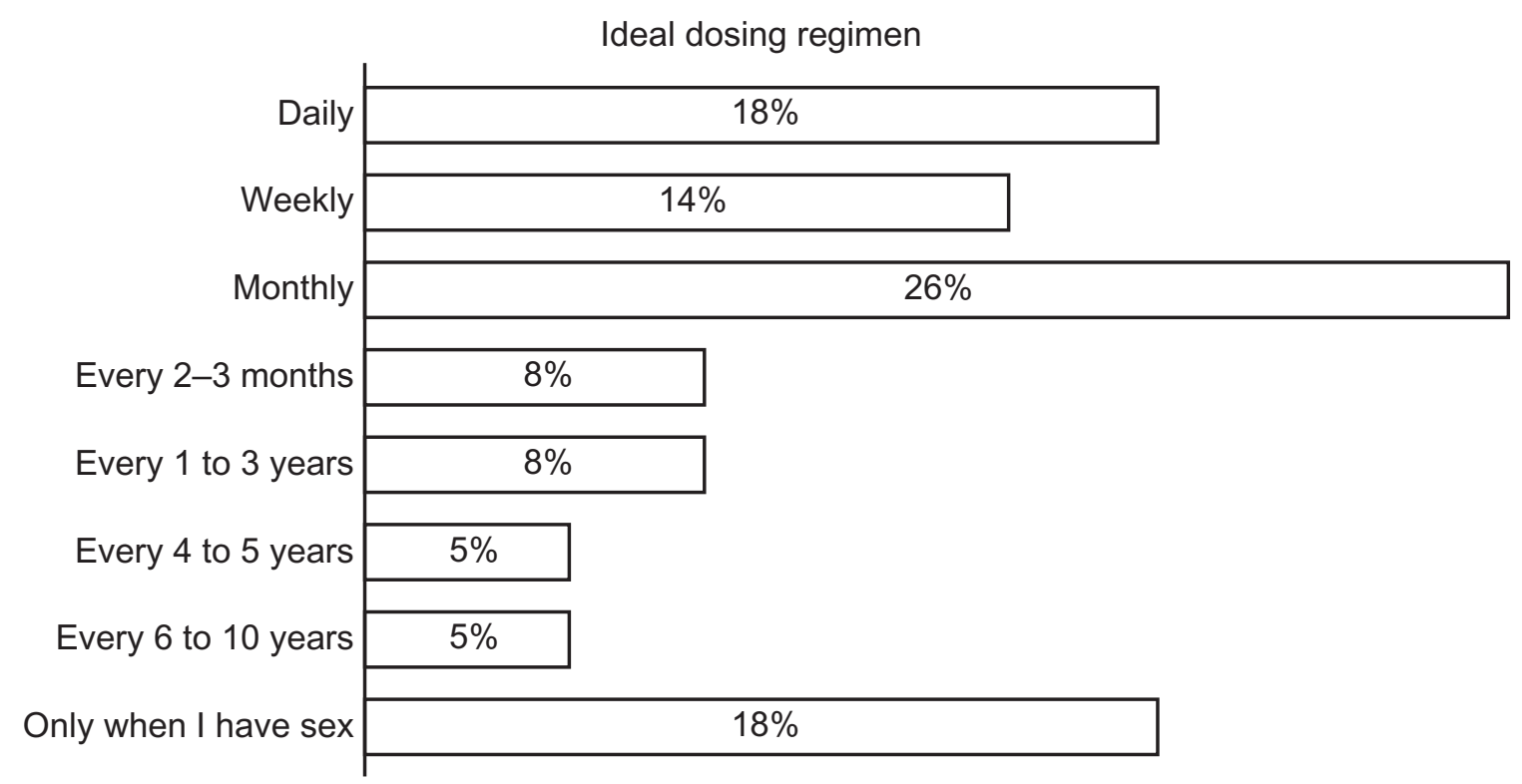

Figure 3 Responses to the survey question on the preferred dosing regimen for a contraceptive method. Responses to the questions were binary (yes/no).

In addition, $67 \%$ of respondents perceived it a reassuring sign that they were not pregnant (ranging from 5\% in Germany to $72 \%$ in the USA).

The majority of women (73\%) replied that they were satisfied with their current contraceptive method, and 20\% stated that they would not switch methods. Indeed, $42 \%$ of women reported that switching would be a "hassle". Factors that would prompt women to change their contraceptive included not needing to take it every day (43\%), the option of a new contraceptive offering additional benefits relative to their current regimen $(42 \%)$ and a new contraceptive being more comfortable than their present choice (38\%, Figure 4).

Women who indicated that they did not use hormonal contraception in the previous year provided reasons for this, including no longer being sexually active (17\%), pregnancy or recent birth, breastfeeding (14\%), and high cost (9\%).

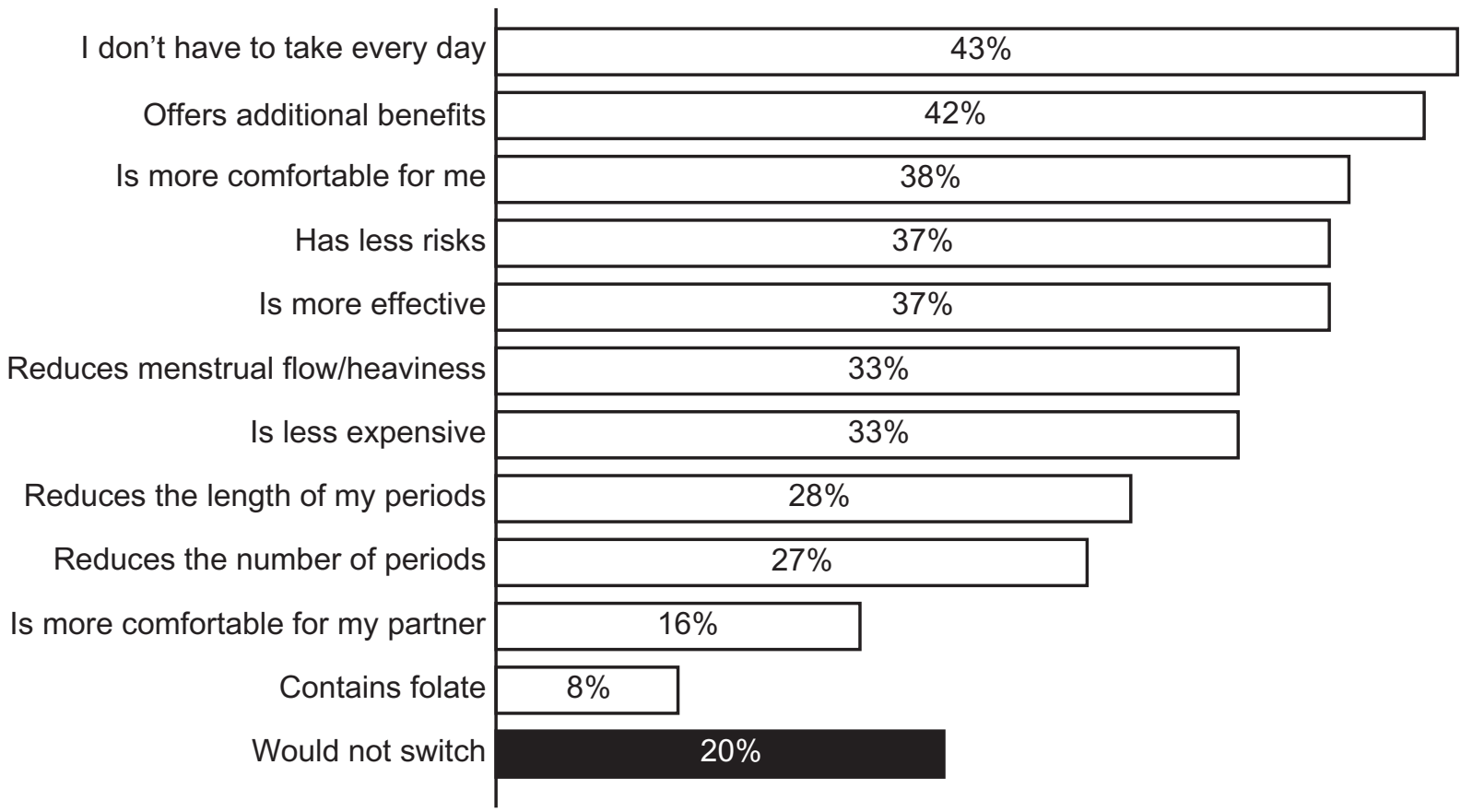

Figure 4 Factors that would prompt women to change their contraceptive. Responses to the questions were given on a seven-point scale (I, complete disagreement; 7, complete agreement). 
In all, $13 \%$ of women indicated that they stopped using hormonal contraception because they were tired of taking it every day, and $9 \%$ indicated that they stopped because they often forgot to take it.

Globally, women expressed concern about the impact of the hormones in their contraception. These concerns included worry about potential long-term effects (46\%), impact on future fertility (42\%), and decreased libido (41\%). Almost half of women (49\%) indicated a preference for a low dose of hormones, although $30 \%$ stated that a higher dose would be acceptable if it reduced intracyclic bleeding.

Regarding shorter-term (less than a year) contraceptive methods, $48 \%$ of women would prefer to change to an OC (Table 2). Of these women, 79\% regarded OCs as a reliable method of contraception. However, $52 \%$ of respondents conveyed frustration in relation to the difficulty of taking a pill at the same time every day and $78 \%$ of respondents admitted to missing at least one pill each year. In addition, $26 \%$ of women missed from three to six pills per year (Figure 5A). Discontinuation was found to be relatively high among pill users, with $29 \%$ of women reporting discontinuation of their OC use in any given year, and 20\% reporting discontinuation due to compliance issues or the burden associated with daily pill intake (Figure 5B and C). Furthermore, 49\% of women reported that, ideally, they would choose a method of contraception that did not involve daily intake.

\section{Opinions on available contraceptive options}

Women were also asked to identify attributes for the following contraceptive methods: male condom, vaginal ring, transdermal patch, injection, intrauterine system/intrauterine device, and implant. Users of short-term methods, such as the ring, patch, and injection, were found to have a more positive view of these methods than nonusers. For example, 24\% of women who had used a vaginal ring were worried that it may fall out, compared with $45 \%$ of all respondents, and $33 \%$ of ring users were worried that their partner would feel it, compared with $38 \%$ of all respondents. Among women who had heard of the patch, there were concerns about discretion (51\%) and the potential for the patch to fall off (50\%), with a similar frequency among users and nonusers. Injections caused concerns regarding weight gain and the required quarterly visits to a health care professional.

Long-term methods were used by $8.5 \%$ of women surveyed. The primary worries expressed were the fear that intrauterine contraceptives would be painful (users, 31\%; all respondents, 43\%), while one third of women expressed concerns regarding implants, particularly fears that they would be bothered by feeling it and that the implant may not be effective. Occasion-based methods, such as the male condom and natural methods, accounted for $33 \%$ of primary usage among responders.

\section{Discussion}

This study was an international survey comprising 12,094 women sampled from across Brazil, Europe, and the USA. The study was conducted to gain an up-to-date global insight into women's contraceptive behavior, as well as their unmet contraceptive needs. The most commonly used contraceptives were hormonal or barrier methods, with $73 \%$ of women confirming that they were happy with their current method. Main drivers of contraceptive choice were efficacy, impact on health and well-being, and cost. Despite a wide variation in the cultural background of participants, results were generally similar between the different countries and regions, and

Table 2 Respondent views on specific attributes of currently available contraceptives. Responses to the questions were binary (yes/no)

\begin{tabular}{|c|c|c|c|c|c|c|c|}
\hline & \multicolumn{7}{|c|}{ Contraceptive method (\%) } \\
\hline & Pill & Male condom & IUD/IUS & Injection & Implant & Patch & Ring \\
\hline Is the form that I most prefer & 48 & 18 & 12 & 7 & 5 & 6 & 4 \\
\hline Is the trendiest & 35 & 10 & 10 & 8 & 14 & II & II \\
\hline Most effective & 53 & 16 & 15 & 7 & 5 & I & 2 \\
\hline Used by majority of my friends & 72 & 15 & 5 & 3 & I & I & 2 \\
\hline Most likely recommended by HCP & 67 & 9 & II & 5 & 2 & 2 & 4 \\
\hline Has the least side effects & 22 & 58 & 8 & 3 & 2 & 3 & 4 \\
\hline Most convenient dosing regimen & 47 & 18 & 12 & 8 & 5 & 5 & 5 \\
\hline Reduces menstrual bleeding & 71 & 2 & 10 & 8 & 4 & 2 & 3 \\
\hline Is the healthiest for my body & 24 & 56 & 8 & 3 & 2 & 3 & 4 \\
\hline Is easiest to use properly & 41 & 20 & 13 & 10 & 7 & 6 & 3 \\
\hline Is most worry-free & 39 & 17 & 18 & 10 & 9 & 3 & 4 \\
\hline Is the best value for my money & 46 & 33 & 10 & 5 & 3 & 2 & 2 \\
\hline
\end{tabular}

Abbreviations: IUD/IUS, intrauterine device/system; HCP, health care provider. 

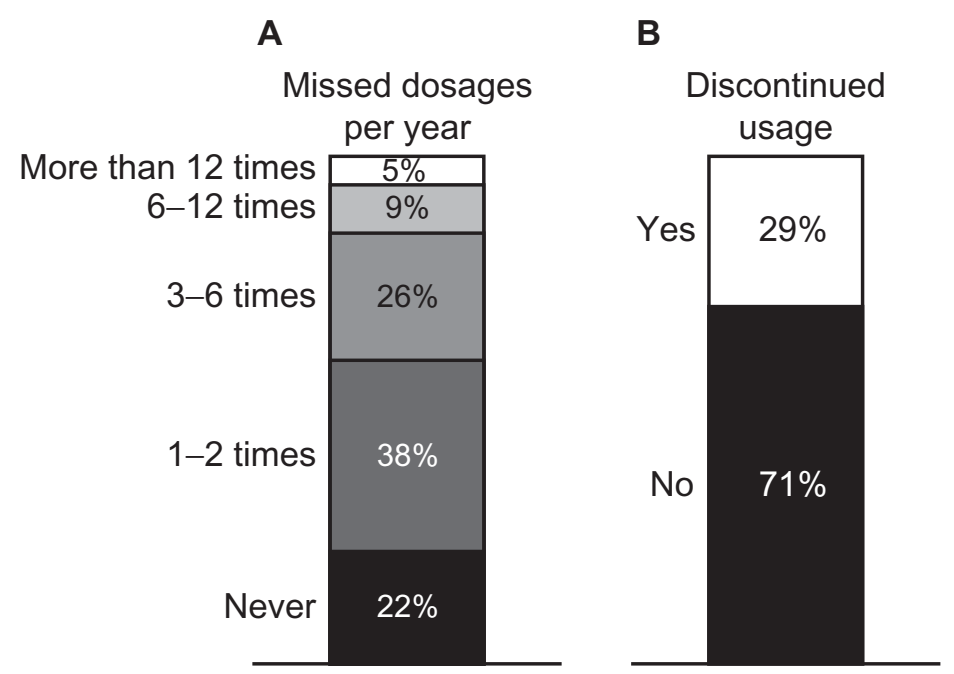

C

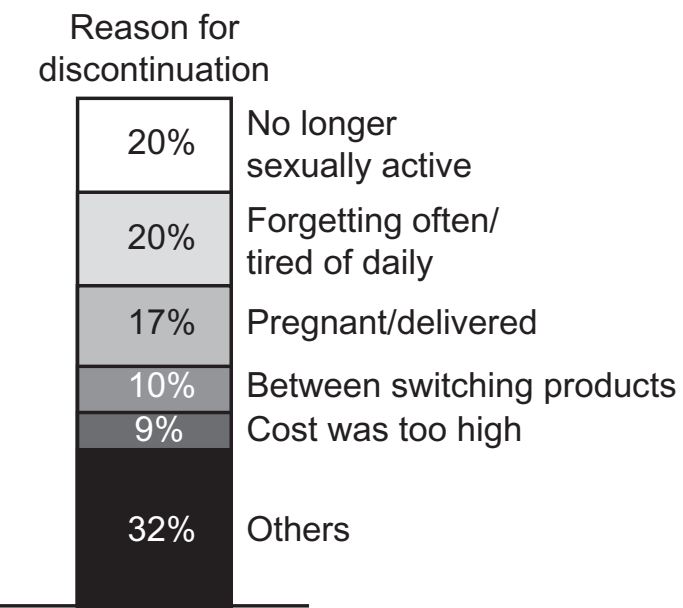

Figure 5 (A) Missed doses of oral contraceptive per year; (B) discontinuation of oral contraceptives per year; and (C) reasons for discontinuation of oral contraceptive. Responses to the questions were binary (yes/no).

indicated that nearly half of respondents would prefer a nondaily method. The survey results indicate that significant parts of the contraceptive market are not well catered for by once-daily hormonal contraception; however, women continue to choose this method. These results are in line with those of previous studies showing that OCs and male condoms are the most commonly used methods of contraception., ${ }^{2,49-11}$

Despite the dominance of OCs in this survey, the majority of women admitted to missing pills, often on a regular basis. Again, these results are in line with those of previous studies showing noncompliant behavior as a common occurrence amongst OC users. ${ }^{2,12}$ Although most users were highly satisfied with their contraceptive pills, they also expressed frustration with a daily dosing regimen. Women's unwillingness to change their method of contraception, as indicated by the $42 \%$ of responders who viewed switching methods as a "hassle", as well as a lack of proper counseling on alternative methods, may be responsible for the continuation of OC use irrespective of frustrations associated with daily intake. This, in addition to patterns of nonadherence, emphasizes the continuing unmet need for education on and access to contraceptive options that improve compliance while minimizing the dosing frequency. However, while long-term contraceptives, such as intrauterine contraceptives and implants, do not rely on the user for efficacy, interest in these methods was found to be relatively low in the current survey, as in other studies. ${ }^{9}{ }^{9,14}$ Evidence indicates that women prefer contraceptives that they can stop taking as soon as they choose to do so., ${ }^{4}, 15$

These results must be reconciled with the fact that this survey, and along with other studies, has shown that efficacy is the greatest priority for women when choosing a contraceptive method. ${ }^{4,15}$ In this study, $76 \%$ of women identified this as one of the most important factors when choosing a method of contraception. While women appreciate the efficacy and dosing regimen of long-term contraceptives, most prefer short-term methods. Over two thirds of women favor having a monthly period, as this is perceived as a sign that they are healthy and not pregnant. As such, there remains a need for short-term, nondaily contraceptive options with proven efficacy and reliability, which maintain the normal monthly pattern of menstrual bleeding.

This survey showed that women hold various opinions on currently available contraceptive options. Most methods, whether short-term or long-term, induced some concerns, although current users of a particular method tended to be more comfortable with it than nonusers. Short-term methods did lead to concerns, such as the possibility of a vaginal ring falling out, or issues of weight gain with injections, but users were less concerned than nonusers, and appeared to have fewer misconceptions about usage. Overall, such misconceptions amongst women highlight a need for provision of more accurate information on their contraceptive options. Long-term methods were used by fewer than $10 \%$ of respondents, with women voicing concerns about pain on insertion and concerns about their efficacy. Health care professionals can help to dispel misconceptions, especially in the USA, where three of four respondents stated that they follow their health care professional's recommendation when deciding on their method of contraception.

In addition, women expressed a general discomfort with regard to hormone intake. Almost half of the women surveyed indicated a preference for contraceptives with a low dose of 
hormone, and this appeared to be driven by a concern about the impact of hormones on well-being, including long-term effects and future fertility. Responses also indicated that women desire a regular menstrual cycle. Indeed, half of the women surveyed regarded a regular period as healthy, and one third reported that they would prefer higher doses of contraceptive hormones rather than experience menstrual spotting, suggesting that the latter may be troublesome to premenopausal women.

Limitations of this study that need to be considered include a lack of external validity owing to the nature of the sampling procedure; respondents were self-selected in the sense that they had previously indicated a willingness to answer online questionnaires, and as a result may not be representative of contraceptive users as a whole. In addition, a large proportion (almost half) of the sample population comprised respondents from the USA. However, this was designed to reflect the importance of US contraceptive users to the worldwide market, with approximately $50 \%$ of sales coming from this nation. It could also be argued that anonymous survey data may not accurately reflect the behavior of the population in a real-world setting. While this may be true to some extent, gathering data in this way is valuable because it allows women to respond more openly compared with face-to-face surveys. Nevertheless, future studies could potentially benefit from focusing on the use of direct discussions or telephone interviews to determine the attitudes of female contraceptive users. Convergent findings would lend support to the conclusions reported here, while also contributing to a valuable field of research.

To summarize, the vast majority of women use OCs as their contraceptive method of choice. While there is a high level of satisfaction with the pill, there are clear signs that daily intake is a burden to many women, resulting in irregular and sometimes ineffective usage. Given that around half of women expressed a wish to conceive in the near future, it was unsurprising that almost half of those surveyed indicated they would ideally choose a short-term, nondaily contraceptive method. A similar proportion of women also indicated that they viewed regular menstruation as a positive feature. Providing women with adequate information on available contraceptive options will enable them to choose the method that best suits their needs and preferences.

\section{Acknowledgments}

The author would like to thank Monitor Deloitte, London, UK, for support with market research data, and Ogilvy 4D,
Oxford, UK, for providing editorial assistance with this manuscript.

\section{Disclosure}

Financial support for this study was provided by Bayer HealthCare AG. The author has received financial support to attend pharmaceutical advisory board meetings, undertake research studies, and speak at educational meetings and conferences, along with travel grants from Astellas, Bayer, Consilient Healthcare, HRA Pharma, Merck, Pfizer, and Vifor Pharma.

\section{References}

1. Klima CS. Unintended pregnancy. Consequences and solutions for a worldwide problem. J Nurse Midwifery. 1998;43:483-491.

2. Jakimiuk AJ, Crosignani PG, Chernev T, et al. High levels of women's satisfaction and compliance with transdermal contraception: results from a European multinational, 6-month study. Gynecol Endocrinol. 2011;27:849-856.

3. Hooper DJ. Attitudes, awareness, compliance and preferences among hormonal contraception users: a global, cross-sectional, selfadministered, online survey. Clin Drug Investig. 2010;30:749-763.

4. Glasier A, Scorer J, Bigrigg A. Attitudes of women in Scotland to contraception: a qualitative study to explore the acceptability of longacting methods. J Fam Plann Reprod Health Care. 2008;34:213-217.

5. Beligotti F, Gordon K. Findings from the International I Plan On... Survey: women's awareness, misconceptions, and preferences regarding their contraceptive options [poster abstract]. Eur J Contracept Reprod Health Care. 2012;17(S1):S98.

6. Egarter C, Frey Tirri B, Bitzer J, et al. Women's perceptions and reasons for choosing the pill, patch, or ring in the CHOICE study: a crosssectional survey of contraceptive method selection after counseling. BMC Womens Health. 2013;13:9.

7. Dunson DB, Colombo B, Baird DD. Changes with age in the level and duration of fertility in the menstrual cycle. Hum Reprod. 2002;17: 1399-1403.

8. Prescription Medicines Code of Practice Authority. Non-interventional studies of marketed medicines - Clause 13 [serial on the Internet]. 2013. Available from: http://www.pmcpa.org.uk/thecode/interactivecode/ Pages/clause13.aspx. Accessed November 25, 2013.

9. Rosales C, Mansour D, Cox MA. Does current contraceptive choice correspond with user satisfaction? J Obstet Gynaecol. 2012;32: $166-172$.

10. Skouby SO. Contraceptive use and behavior in the 21 st century: a comprehensive study across five European countries. Eur J Contracept Reprod Health Care. 2004;15 Suppl 2:S42-S53.

11. Cibula D. Women's contraceptive practices and sexual behaviour in Europe. Eur J Contracept Reprod Health Care. 2008;13:362-375.

12. Aubeny E, Buhler M, Colau JC, et al. The Coraliance study: noncompliant behavior. Results after a 6-month follow-up of patients on oral contraceptives. Eur J Contracept Reprod Health Care. 2004;9: 267-277.

13. Mitka M. IUDs effective but underused options for emergency and long-term contraception. JAMA. 2012;307:2473-2474.

14. Espey E, Ogburn T. Long-acting reversible contraceptives: intrauterine devices and the contraceptive implant. Obstet Gynecol. 2011;117: 705-719.

15. Say R, Mansour D. Contraceptive choice for young people. J Fam Plann Reprod Health Care. 2009;35:81-85. 
International Journal of Women's Health

Dovepress

\section{Publish your work in this journal}

The International Journal of Women's Health is an international, peerreviewed open-access journal publishing original research, reports, editorials, reviews and commentaries on all aspects of women's healthcare including gynecology, obstetrics, and breast cancer. The manuscript management system is completely online and includes Visit http://www.dovepress.com/testimonials.php to read real quotes from published authors.

Submit your manuscript here: http://www.dovepress.com/international-journal-of-womens-health-journal 